\title{
SHORT REVIEW
}

\section{The interaction between developmental bias and natural selection: from centipede segments to a general hypothesis}

\author{
W Arthur \\ Ecology Centre, University of Sunderland, Sunderland, UK
}

Do limitations to the ways in which mutations can alter developmental processes help to determine the direction of phenotypic evolution? In the early days of neo-Darwinism, the answer given to this question was an emphatic 'no'. However, recent work, both theoretical and empirical, argues that the answer should at least be 'sometimes', and possibly even a straightforward 'yes'. Here, I examine the key concept of developmental bias, which encompasses both developmental constraint and developmental drive. I review the case of centipede segment number, which is a particularly clear example of developmental bias, but also a rather unusual one. I then consider how, in general terms, develop- mental bias and natural selection might interact, with the result that it is their interaction, rather than either process on its own, that determines evolutionary direction. Essentially, the whole argument is about the extent to which phenotypic variation is developmentally structured as opposed to amorphous or random. This issue can be traced back to the very beginning of evolutionary biology, and in particular to a difference of opinion between Darwin and Wallace, who emphasized, respectively, character correlation and character independence.

Heredity (2002) 89, 239-246. doi:10.1038/sj.hdy.6800139

Keywords: developmental constraint; developmental bias; developmental drive; centipede; segment; adaptive landscape

\section{Introduction}

The evolutionary role of developmental constraint has long been controversial. Advocates of constraint have been critical of what they see as the panselectionist approach of neo-Darwinians (Gould and Lewontin, 1979). However, such advocates have themselves been criticized for adopting an overly simplistic view of neoDarwinism (Dawkins, 1986). It has been argued that neoDarwinian theory encompasses developmental constraints (Cheverud, 1984). This point is also made by Wagner (1988), but with an important qualification. He states: 'It is true that the concept of developmental constraints is implicitly contained in neo-Darwinian theory. Nevertheless, it is also true that this concept has almost never had an influence on the main stream of research that was done by neo-Darwinists'. Although much has changed in evolutionary biology since the late 1980s, it remains true that developmental constraint does not play a central role in the work of most population geneticists.

Progress in establishing the evolutionary role of developmental constraints has been hampered by two things: terminological problems and lack of clear, unambiguous examples. Here, I address both of these issues. I provide definitions that correspond with most, but not all, prior usage. I then discuss the example of constraint in centi-

Correspondence: W Arthur, Ecology Centre, University of Sunderland, Sunderland SR1 3SD, UK. E-mail: wallace.arthur@sunderland.ac.uk Received March 2002; accepted May 2002 pede segment number, which is particularly clear in that an alternative selective explanation for the pattern of character states observed is highly implausible. I conclude by considering the general role of constraint in determining, in conjunction with natural selection, the direction of evolutionary change.

\section{Bias, constraint and drive}

The most commonly quoted definition of developmental constraint is that provided by Maynard Smith et al (1985): 'A developmental constraint is a bias on the production of variant phenotypes or a limitation on phenotypic variability caused by the structure, character, composition or dynamics of the developmental system'. Notice that these authors use both 'bias', which can include positive and negative effects, and 'limitation', which implies restriction, and hence a solely negative effect. Unfortunately, this problem is reflected in the literature more widely, with most authors using constraint in the negative sense of restrictions on the available variation, but others (eg, Gould, 1989) urging the inclusion of positive effects as well.

This problem can be readily solved by using 'developmental bias' as the umbrella term for both positive and negative effects, while restricting the use of 'developmental constraint' to negative effects alone. However, if we adopt this approach, it makes sense to have a term for positive effects, and I have proposed that 'developmental drive' (Arthur, 2001) be used for this purpose. Note that developmental drive is quite distinct from meiotic drive 
(eg, Geliva, 1987), molecular drive (Dover, 1982) and dominance drive (Mallet, 1986).

It might be argued that developmental drive is a redundant term, because where there is constraint in relation to some ontogenies/phenotypes there must necessarily be drive towards others. But while this latter point is true, it helps to be able to refer, in any given situation, to a particular phenotype and describe it as driven or constrained, in the same way that in a selective scenario we wish to be able to describe a particular phenotype as being selected for or against; that is, subject to positive or negative selection. Although the equivalent use of positive and negative constraint is an option (Gould, 1989), 'positive constraint' is in my view a rather confusing term; hence the introduction of developmental drive.

There is, however, another problem: the distinction between relative and absolute constraint. If a developmental system is entirely incapable of producing a certain kind of variant ontogeny, then we have an absolute constraint. If, on the other hand, 'ontogeny $x^{\prime}$ is merely difficult to produce, in the sense that a small proportion of mutations lead in that direction while many lead elsewhere, then we have relative constraint. The same distinction can be applied to positive biases, ie to developmental drive, though the notion of absolute drive may at first seem odd because it implies that all changes in ontogeny are driven in a particular direction. However, this is indeed possible, especially when the direction specified is a broad one. As we will see below, all variant centipede ontogenies, from whatever starting point, are driven into odd-segment-number character states. So there is absolute drive in this direction, and equivalently absolute constraint regarding even numbers of segments.

These definitions are summarized in Table 1 . As noted above, they correspond with most but not all usage. Since the terminology has not yet settled down, it is worth watching out for alternative usages which are potentially confusing, though it is usually apparent from the context what the authors actually mean. Finally, it should be noted that the above thoughts on definitions are highly selective. Anyone wishing to pursue issues about the definition of constraint more widely should consult Antonovics and Van Tienderen (1991), Resnik (1995), Schwenk (1995) and Fusco (2001).

Table 1 Types of developmental bias

\begin{tabular}{|c|c|c|}
\hline $\begin{array}{l}\text { Positive vs negative } \\
\text { effects }\end{array}$ & $\begin{array}{l}\text { Some phenotypes } \\
\text { can be produced, } \\
\text { others cannot }\end{array}$ & $\begin{array}{l}\text { Some phenotypes } \\
\text { are 'easier' to } \\
\text { produce than others }\end{array}$ \\
\hline $\begin{array}{l}\text { Positive and negative } \\
\text { effects considered } \\
\text { together }\end{array}$ & Absolute bias & Relative bias \\
\hline $\begin{array}{l}\text { Negative effects } \\
\text { considered alone }\end{array}$ & $\begin{array}{l}\text { Absolute } \\
\text { constraint }\end{array}$ & $\begin{array}{l}\text { Relative } \\
\text { constraint }\end{array}$ \\
\hline $\begin{array}{l}\text { Positive effects } \\
\text { considered alone }\end{array}$ & Absolute drive & Relative drive \\
\hline
\end{tabular}

See text for explanation. Note that absolute constraint and absolute drive necessarily co-occur, as do relative constraint and relative drive. That is, the form of one of the components of bias dictates the form of the other, as they can only be measured in a comparative way. (Dworkin et al (2001) use qualitative and quantitative in the same way that I use absolute and relative.)

\section{Developmental bias in centipede segment number}

\section{Evidence for absolute bias}

The basic observation here is that although there are at least 3000 species of centipede (Lewis, 1981), and although their trunk segment numbers range from 15 to 191 (Minelli and Bortoletto, 1988; Arthur, 1999; Minelli et al, 2000), there is no centipede species that is characterized by an even number of trunk segments. This is true despite the existence of old records of frequent even numbers (eg, in Bateson, 1894), which are simply wrong. If you select a centipede species at random and count the number of leg-bearing (= trunk) segments in 100 individuals, these numbers will all be odd, even assuming that the species you have chosen is one of those that exhibit considerable intraspecific variation. Only a single individual of a single species has ever been shown to have an even number of trunk segments (Kettle et al, 1999, 2000), and there is a very specific reason for this: the specimen concerned was a homeotic mutant in which the intercalary segment that precedes the genital region was transformed into a duplicate of the final leg-bearing segment.

This complete lack of even numbers of trunk segments contrasts not just with the wide range of odd numbers that is found, but with the density with which this range of odd numbers is populated. Only at the lowermost and uppermost ends of the scale do we find missing values. These are: 17, 19, 25; and 179-189 inclusive (Minelli and Bortoletto, 1988; Arthur, 1999). Overall, then, this counts as a clear and unambiguous case of developmental bias (Arthur and Farrow, 1999) unless there is some as-yet unknown form of selection against any even-numbered variants, which seems highly implausible.

\section{The nature of the developmental system and the question of what exactly is being constrained}

I will now focus on the two most speciose (out of five) orders, Lithobiomorpha and Geophilomorpha (see Figure 1 ), which are characterized by very different developmental systems and yet exhibit the same apparently absolute constraint regarding even-segment-number phenotypes.

Lithobiomorpha: This group of about 1100 species includes the familiar garden centipede Lithobius forficatus. All have 15 trunk segments when adult. However, all hatch from the egg with fewer than this; they add segments during a series of moults through which the hatchling grows towards adulthood. The pattern of segment addition has been described for Lithobius variegatus (Eason, 1964) and Lithobius forficatus (Andersson, 1976). These two accounts concur, except that Anderson has an additional stage (numbered 'zero') that occurs before Eason's 'first-larval' stage. This is unlikely to be a real difference between the species. Rather, as Anderson states, 'the first stadium has been ignored' by many authors ( $p$ 161). The way segments are added is shown in Table 2, and this pattern may well be standard for Lithobius. Whether it is standard throughout the Lithobiomorpha remains to be seen.

Regardless of the answer to this question, what the data in Table 2 show is that lithobiomorph centipedes 

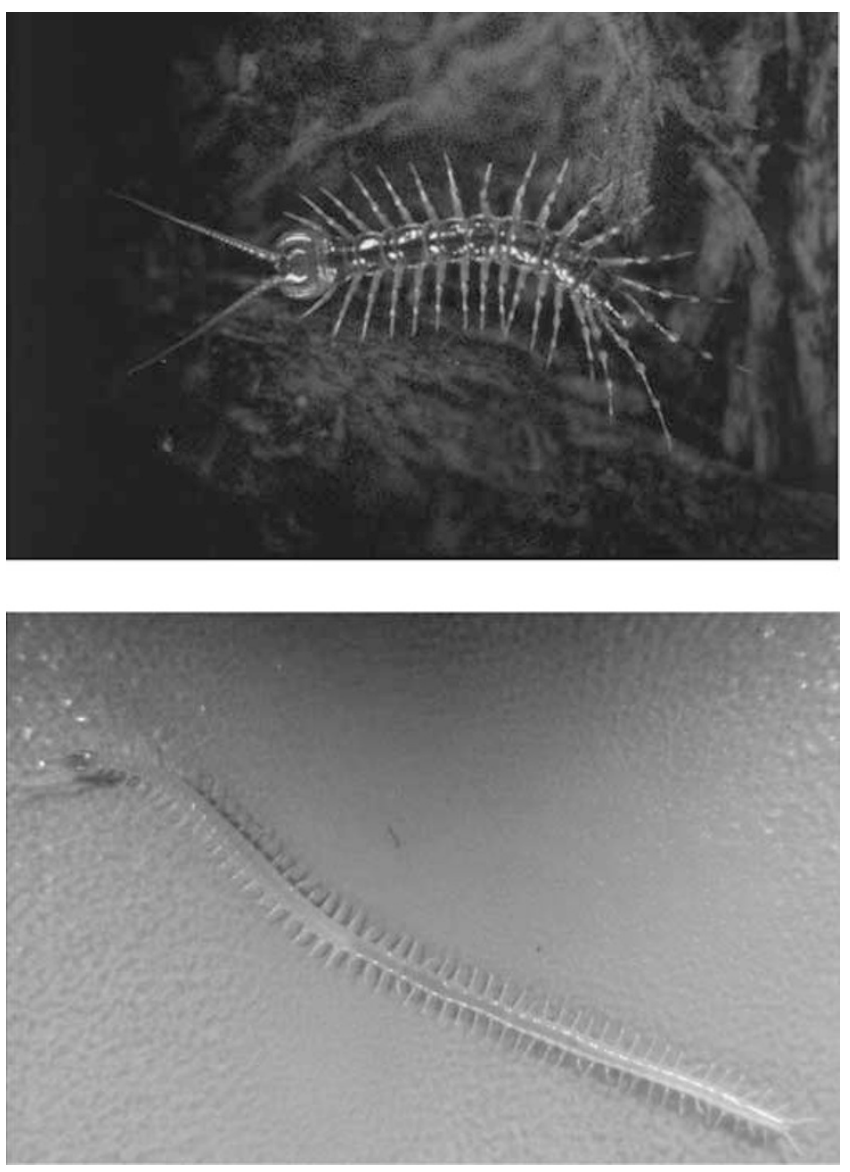

Figure 1 Representative species of the centipede orders Lithobiomorpha (Lithobius variegatus, top) and Geophilomorpha (Geophilus insculptus, bottom). In the former order, the number of trunk segments, and hence leg-pairs, is fixed at 15 for all species. In the latter, the number is variable both within and between species (eg it varies between 45 and 53 for G. insculptus). The intraspecific variation includes both sexual dimorphism and variation within each sex, and appears to be predominantly heritable (Kettle et al, 2002).

Table 2 Pattern of posterior segment addition during postembryonic growth in Lithobius ${ }^{\mathrm{a}}$

\begin{tabular}{lcc}
\hline $\begin{array}{l}\text { Developmental } \\
\text { stage }^{\mathrm{b}}\end{array}$ & $\begin{array}{c}\text { No. of pairs } \\
\text { of legs }\end{array}$ & $\begin{array}{c}\text { No. of pairs } \\
\text { of limb buds }\end{array}$ \\
\hline L0 & 7 & 1 \\
L1 & $8^{\mathrm{c}}$ & 2 \\
L2 & 8 & 2 \\
L3 & 10 & 2 \\
L4 & 12 & 3 \\
Adult & 15 & 0 \\
\hline
\end{tabular}

a Data for Lithobius forficatus (Andersson, 1976) and Lithobius variegatus (Eason, 1964). Also, the hatchling (L0) of Lithobius atkinsoni has recently been shown to have the $7+1$ arrangement (Hughes and Kaufman, 2002).

'These are referred to as 'larval' (hence L), though 'juvenile' might be a better term.

'One of these leg-pairs is about half-developed (Andersson, 1976). with even numbers of trunk segments (and hence legpairs) exist, but only as juveniles. The strange thing about this is why, given the all-pervasive role of heterochrony in evolution (Gould, 1977; McKinney and MacNamara, 1991), there have been no shifts of relative timing so that reproductive maturity and a cessation of segment addition have occurred in (say) a 12-trunk-segment juvenile in at least one of the many lithobiomorph species. Might such variants have occurred from time to time but simply never been fit? There is no evidence for this, but it cannot be ruled out. So the argument for constraint is persuasive but not conclusive. It becomes even more persuasive when we consider the geophilomorph situation.

Geophilomorpha: In this group of about 1000 species the timing of segment formation is very different. Despite the larger number of segments in geophilomorphs (up to 191, as noted above), all are formed during embryonic development. The tiny hatchling has its full adult complement of segments. Although postembryonic growth involves a series of moults, and some morphological changes accompany these (eg increased numbers of coxal pores), there is no postembryonic segment proliferation zone, and no segments are added at any moult in any geophilomorph species. The occasional claims to the contrary (Archey, 1936; Misioch, 1978) have been shown to be incorrect (Minelli, 1985; Horneland and Meidell, 1986; Kettle et al, 2002).

As if in response to Raff's (1996) statement that the discovery of shared regulatory genes 'has already begun the process of bringing such nonstandard animals as crayfishes and centipedes into the experimental mainstream', there have been several recent studies of the developmental genetics of centipedes. Some of these (Bastianello et al, 2002; Hughes and Kaufman, 2002) involve Hox genes and so do not directly concern us here. However, others (Bastianello and Minelli, 2001; Kettle et al, 2002) focused on the segmentation gene engrailed and so are relevant to the formation of segments and the determination of segment number. The study by Kettle et al (2002) is particularly relevant because it goes beyond gene sequence data to visualization of the pattern of expression of engrailed in geophilomorph embryos. It is clear from this study that segmental stripes of engrailed expression form in strict anteroposterior sequence. Moreover, the stripes appear one at a time, not in pairs. Eventually, this headto-tail process concludes when the posteriormost stripe of expression occurs just in front of the telson.

It would seem reasonable to expect that such a one-ata-time process could be stopped at any point - that is, after the formation of any given number of segmental expression stripes. Even if there is some reason why it cannot, the final rudimentary segment (or any other, for that matter) could be deleted by apoptosis, in the same way that occurs in the interdigital regions of tissue in tetrapods. Yet clearly, neither stopping the process at any even-number stage nor later reducing any odd number to a lower even number ever occurs. The obvious question is: why not?

\section{A possible mechanism}

It is conventional, in myriapodology, to consider the centipede trunk as corresponding to the long series of leg-bearing segments that constitutes the bulk of the animal. However, between the head and the first leg-bearing 
segment is the forcipular segment bearing the poison claws (or forcipules or maxillipeds). The poison claws appear to be modified legs rather than modified mouthparts (Hughes and Kaufman, 2002). Therefore, it is not unreasonable to include the forcipular segment as part of the trunk. If we take this approach, then the trunk always has an even, rather than an odd, number of segments. It has been proposed (Minelli, 2000) that centipede segments are established through a multiplicative process wherein a small number of initial repeating units or 'eosegments' are later subdivided into a greater number of 'merosegments'. Any such multiplicative process would routinely produce an even-number outcome, so such a developmental mechanism might underlie the constraint that we observe. However: (a) there is no evidence yet of a multiplicative process of this kind; (b) it would have to operate upstream of engrailed expression which clearly occurs in an additive rather than multiplicative way; and (c) it still would not explain why processes such as heterochrony or apoptosis could not secondarily alter the outcome. So we must conclude that at present the observed constraint cannot be adequately explained.

\section{The interaction with natural selection}

Although the mechanism is not yet clear, the conclusion that the absence of even numbers of trunk segments constitutes an example of absolute bias (see Table 1) seems inevitable. But this bias does not, on its own, determine the array of character states (ie trunk segment numbers) that exists in nature. Rather, this array is determined by bias and selection together. This can be seen from a comparison of the typical range of segment numbers in closely-related species.

Table 3 shows the range of segment numbers in British Geophilus species, taken from Eason (1964), but modified to take account of the recent discovery of Geophilus easoni (Arthur et al, 2001). Although we do not know the pattern of lineage-splitting that produced these and other Geophilus species, it is clear that speciation events in this genus produce daughter species that at least differ in their modal segment number, even though their ranges may still overlap. One interpretation of this observation is that the differences between species are the result of selection, while the common theme among species of an absence of even numbers of segments is a result of developmental bias.

Table 3 Segment number ranges in British species of Geophilus

\begin{tabular}{lcc}
\hline Species & \multicolumn{2}{c}{ Range of segment numbers } \\
\cline { 2 - 3 } & Males & Females \\
\hline G. insculptus & $45-49$ & $49-53$ \\
G. easoni & $47-49$ & $47-51$ \\
G. carpophagus & $51-55$ & $53-57$ \\
G. fucorum & $51-53$ & $51-57$ \\
G. osquidatum & $53-55$ & $55-63$ \\
G. electricus & $65-69$ & $67-73$ \\
\hline
\end{tabular}

Sources of data: Eason (1964) and Arthur et al (2001). Note that these ranges are for British populations only; the overall species ranges may be greater, especially where there are latitudinal clines (see text).
Support for an influence of selection comes from a latitudinal pattern in the variation. Eason (1964) noted that in geophilomorphs generally, those species living in colder northern climates tend to have fewer segments than those living in warmer southern climates. (The geographical range examined was from Scandinavia to the Middle East and North Africa.) Kettle and Arthur (2000) found a latitudinal cline in segment number in the coastal geophilomorph Strigamia maritima (see also Jeekel, 1964). This cline is in the same direction as the between-species pattern: fewer segments in more northerly populations. Other species show similar, though less pronounced clines (Arthur and Kettle, 2001). It is thus possible that a speciation cycle operates as follows: origin of new species; north-south spread; selection producing clinal variation; fragmentation of distribution; reproductive isolation of 'fragments', each having a restricted range of segment number variation compared with the parent species; north-south spread of each - hence repeating the cycle.

\section{Developmental bias, natural selection and the direction of evolutionary change}

The centipede example discussed above has a highly unusual feature. The missing character states are interspersed among those that are observed in a regular way. This peculiar pattern gives this example both a strength and a weakness. The strength is that it is hard to imagine that the,,,+-+- pattern is caused by anything other than developmental bias, even if we do not yet understand the molecular mechanisms underlying it. The weakness is that the way in which bias interacts with natural selection is perhaps unique and thus hard to generalize from. Consider the situation depicted in Figure 2. This shows the contrast between optimal (top) and actual (bottom) distributions of character states. In this particular case, it can be seen that the optimal phenotype, perhaps determined by manoeuvrability requirements in a particular substrate, cannot be produced. Rather, the commonest character states in the population lie on either side of this. Such a situation would not arise in an unconstrained character such as body size, where, in the absence of other complications, the mean value of the character could evolve to coincide with the fitness maximum. (Note that segment number is not associated with body size: segment number variants within a species have similar size frequency distributions; Kettle and Arthur, 2000.)

In this scenario, bias causes a mis-match between actual and optimal phenotypes, but it does not in any important way control the direction of evolution. The most plausible explanation of the data on congeneric species given in Table 3 is that in response to a new or altered environment, selection moves the distribution of segment numbers upwards or downwards - that is, selection determines the direction of evolution in this character. The role of bias is restricted to the fine-tuning of where the distribution equilibrates.

We now ask the question of whether, in other systems characterized by less bizarre forms of bias, the interaction with selection might operate in a different way, and specifically in a way that involves a major role for developmental bias in determining the direction of phenotypic evolution. Here, I take a general and abstract approach to this question. 


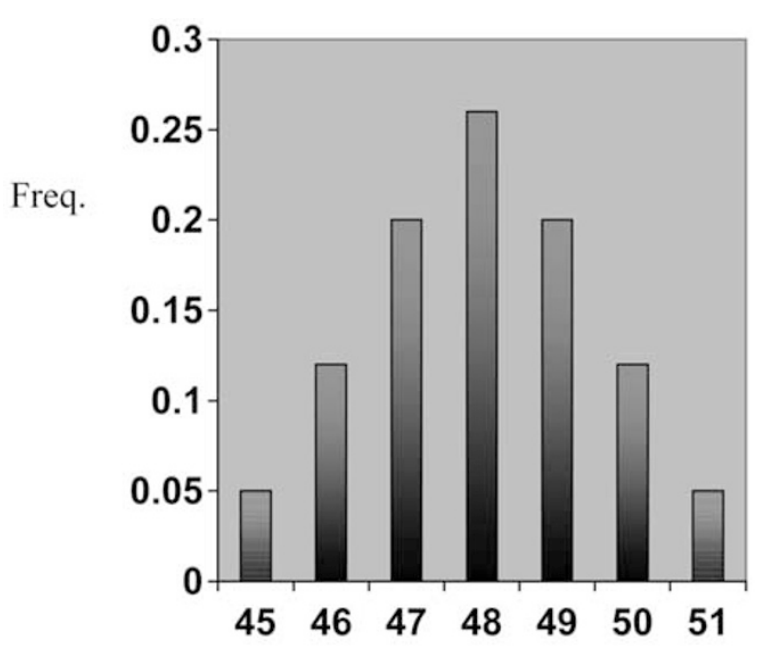

Number of trunk segments

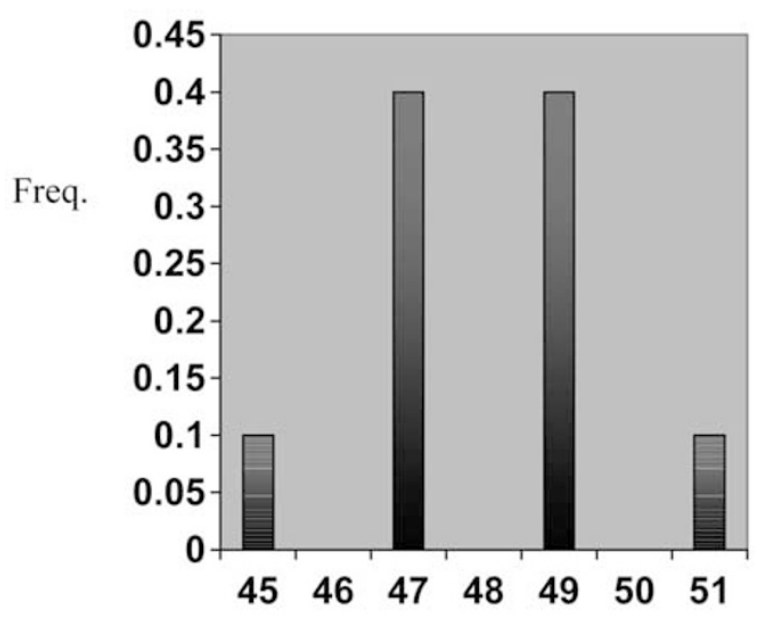

Number of trunk segments

Figure 2 A possible relationship between optimal (top) and actual (bottom) segment numbers for an unspecified population/species of geophilomorph centipede. Since even numbers appear to be developmentally prohibited for reasons not yet established, there will necessarily be a mismatch between optimum and actual modal numbers if the former is even. (Sexual dimorphism is ignored here; see Table 3 for details.)

It is necessary at the outset to distinguish between two kinds of evolutionary changes: (a) those based on standing variation, both genetic and developmental/ phenotypic, already present in the population; and (b) those that can only proceed following the occurrence of a novel mutation. I make the assumption here that most evolution is of the former type, while the latter is infrequent but may, when it does take place, involve more radical changes.

Regarding the latter type of changes, it was asserted in the early days of neo-Darwinism that mutation did not play a role in determining evolutionary direction. Fisher (1930) speaks of a 'logical case for rejecting the assumption that the direction of evolutionary change is governed by the direction in which mutations are taking place, and thereby rejecting the whole group of theories in which this assumption is implicit'. And Ford (1971) states: 'if ever it could have been thought that mutation is important in the control of evolution, it is impossible to think so now'. Given that Fisher and Ford were reacting against an array of theories that we continue to believe are wrong, namely neo-Lamarkism, orthogenesis and macromutationism, it is hard not to sympathize with them in a general way. However, their rejection of a directional role for mutation went too far. Yampolsky and Stoltzfus (2001) have demonstrated that the order in which mutations occur can indeed determine in a major way the direction in which evolution proceeds. From a genetic perspective, this is 'mutation bias' (the term they use). However, from a phenotypic perspective - ie the ways in which the mutations concerned reprogram development (Arthur, 2000) - it is related to developmental bias.

However, I want to concentrate here on the commoner process of evolution based on standing variation, where changes are not 'waiting' for the input of new mutations, and hence mutational order is not an issue. To visualize this process, it is helpful to take an approach based on adaptive landscapes. I will use a landscape framed by phenotypic characters ' $X$ ' and ' $Y$ ' (Figure 3). Here, the population depicted (shaded) exhibits a positive correlation between the values of $X$ and $Y$, as might be expected if the characters are developmentally connected rather than independent. What Figure 3 shows is that the elliptical pattern of variation resulting from positively correlated character values influences the direction in which the population evolves. Specifically, it will tend to

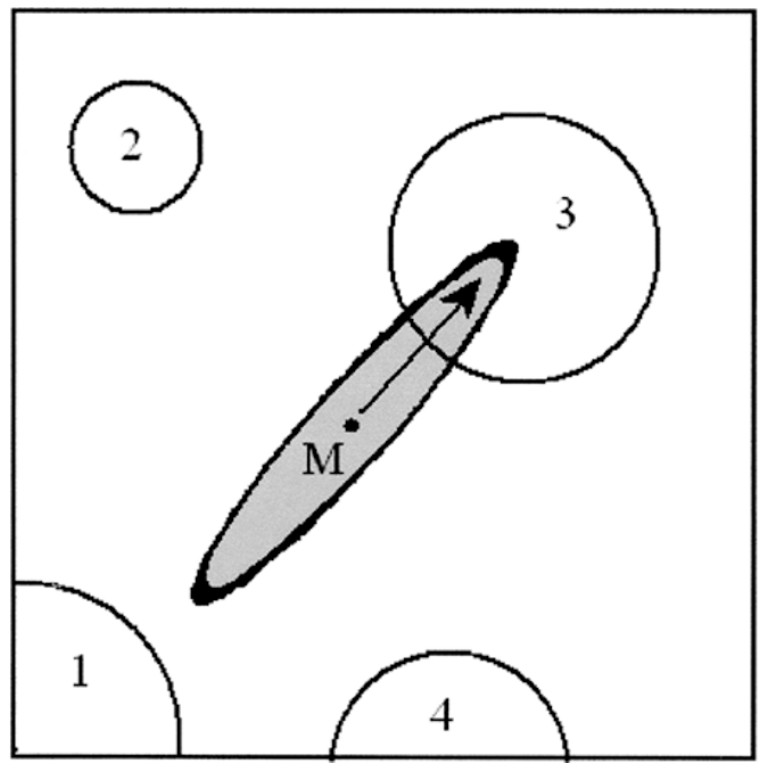

Figure 3 Two-dimensional adaptive landscape where the values of the two phenotypic characters are positively correlated for developmental reasons, giving an elliptical pattern of co-variation in the population (shaded). In the situation shown, the population evolves so that the mean character value $(\mathrm{M})$ climbs peak 3 . Different structuring of the variation could alter the direction in which the population evolves, even if the structure of the landscape remains the same. For simplicity, it is assumed here that fitness changes in a stepwise manner at the contours indicated, while the areas in between contour lines are 'flat' from a fitness perspective. 
move up (pictured) or down the diagonal that runs from bottom-left to top-right. It will generally not move in the orthogonal dimension (ie bottom-right to top-left).

An example which corresponds quite well to this abstract picture is that of forelimb and hindlimb lengths in land-based tetrapods. There is enormous betweenspecies variation, from mice and shrews to elephants and giraffes. Most species have approximately similar lengths of forelimbs and hindlimbs (the latter being only slightly longer, usually), so the between-species variation lies on or near the diagonal. The variation observed within species tends also to be biased in this way. This intraspecific bias may be one reason why the various species have spread along the diagonal rather than exploring other directions. There are exceptions of course, such as tyrannosaurs and kangaroos, but these highly asymmetric designs are a small minority of tetrapod species.

A caveat is necessary at this point. The strength and weakness of this example are reversed compared with the centipede one. The kind of developmental bias involved here may be quite general - this is clearly a strength. But the pattern of character states observed within a species could be due to selection rather than bias. Approximately equal-length forelimbs and hindlimbs constitute a balanced design in engineering terms, and may be selectively favoured. So, especially if measurements are made on adults and an elliptical pattern of co-variation is found, as in Figure 3, this could represent the result of strong selection on more random variation in juveniles. However, it seems much more likely that the reason for such positive co-variation lies in the operation of generalized developmental processes - like growth hormone action - operating throughout the embryo and indeed throughout the body of the juvenile during postembryonic growth. This hypothesis is readily testable by highly replicated measurements of both characters in a series of developmental stages.

The point that I am making here is a simple but important one, namely that the structure of the variation will be a major determinant of evolutionary direction, just as the amount of variation can determine the probability of any evolutionary change occurring in the first place (Kirkpatrick, 1982; Whitlock, 1995). Of course, there are many complications that will need to be superimposed on the basic argument, such as: (a) the fact that in reality adaptive landscapes are highly multidimensional (Gavrilets, 1997); and (b) the existence of fluctuations in environmental variables that render a supposedly fixed landscape rather more of a 'seascape' (Merrell, 1994). Nevertheless, the central point may turn out to be robust in the face of such complications. Furthermore, the adaptive peaks that become available to the population after an initial bout of evolutionary change will be quite different depending on the direction of that initial change. So the long-term cumulative effects of the structure of the phenotypic variation, which is itself at least partly due to developmental bias, are likely to be substantial. That is, different patterns of developmental co-variation of characters will lead to very different evolutionary fates in the distant future.

\section{Discussion}

From a historical perspective, it is clear that proponents of developmental bias incline towards Darwin's (1859) rather than Wallace's $(1870,1897)$ views on the nature of phenotypic variation. Darwin emphasized the connectedness of body parts during development, and the tendency of related parts (eg forelimbs and hindlimbs) to covary; he referred to this as 'correlation of growth'. Wallace, on the other hand, saw variation as essentially unconstrained, and emphasized independence of characters rather than correlation. For example: 'each part or organ varies to a considerable extent independently of other parts' (1897, p 81). Of course, selection can often 'break' correlations, as Darwin was quick to point out. But what I have stressed here (eg in Figure 3) is that the interaction between bias and selection may be such that correlations are often not broken; rather, selection proceeds in what might be described as the line of least resistance.

This point is particularly important, given the recent work of Beldade et al (2002) on butterfly wing pigmentation patterns. These authors use as the basis for an artificial selection experiment positive co-variation in the size of anterior and posterior eyespots on the forewing of the African species Bicyclus anynana, which corresponds well to the abstract picture shown in Figure 3. They demonstrate that despite this strong correlation it is possible to select for butterflies with large anterior eyespots and small posterior ones (or vice versa). They conclude that this result 'argues for a dominant role of natural selection, rather than internal constraint'.

In my view, this conclusion is unjustified. What they have done is to impose one particular artificial adaptive landscape with a stepwise increase in fitness a short distance on either side of, and at right-angles to, the principal diagonal; and it is unsurprising that this produces the result they achieved. My point herein is a broader one, namely that as a species migrates into new environments (or experiences changed conditions in the same environment) it will encounter a wide range of topographies of adaptive landscape. A strong positive correlation between two characters may not influence the direction of phenotypic evolutionary change in some of these (corresponding to the Beldade et al 2002 result), but it will do so in others (as depicted in Figure 3). When it does so, the biased variation achieves its effect through its interaction with natural selection. So it is not a case of developmental bias 'versus' selection, but rather developmental bias and selection.

One of the most important goals for future work on developmental bias is analysis of the molecular mechanisms through which it arises. This has been emphasized, albeit in a rather negative way, by Maynard Smith (1998), who stated that 'merely using the phrase 'developmental constraint' does not help much if one cannot specify what the constraints are or why they exist' (my italics). In the centipede example, the expression pattern of the segment polarity gene engrailed (Kettle et al, 2002) makes it likely that the constraints on segment number arise through molecular mechanisms operating upstream of engrailed, and so in the first 2 weeks of development (out of a 4-week+ embryogenesis and a 4-year+ lifespan). Moreover, because the upstream segmentation genes of Drosophila are well known (Ingham, 1988) and many of them are highly conserved across the arthropods, the target genes for study as possible causes of the observed bias in phenotypic character states belong to a relatively 
small and well-defined group, which should facilitate future work.

A brief reference is necessary to the related concepts of developmental burden (Riedl, 1978) and generative entrenchment (Wimsatt, 1986). These terms were devised to reflect the difficulty of altering early developmental stages because of adverse knock-on consequences for later stages. It is important to note that what is at issue here is the selective constraint of development rather than developmental constraint per se. That is, variations may arise but they are selected against. Although Riedl and Wimsatt thus emphasized negative selection for developmental reasons, Whyte (1965) drew attention to its positive counterpart, namely selection for improved developmental co-ordination. So in the end, rather than viewing phenotypic evolutionary change in a simplistic way selection as a force for change and development as a source of constraint - we can think in terms of a $2 \times 2$ matrix: bias, selection $\times$ positive, negative. And the selection (whether positive or negative) can be for either 'internal' (coadaptation) or 'external' (environmental adaptation) reasons.

The challenge that lies ahead is twofold. We must attempt to unravel the molecular causes of developmental bias, as noted above. But we must also attempt to quantify the interaction between bias and selection, rather than be satisfied with descriptive accounts such as that provided here. This will require a combined modelling approach that treats the developmental dynamics of individuals together with the dynamics of the populations in which those individuals occur. Not an easy task, but one that is necessary for conceptual progress and that will be very stimulating for those few individuals with the skills to undertake it. I wish them luck.

\section{Acknowledgements}

I thank the following: Alessandro Minelli for stimulating my interest in the centipede segmentation system; Michael Richardson and Giuseppe Fusco for helping to re-kindle my interest in developmental constraint; Alec Panchen for critical comments on the draft manuscript; Michael Arthur, James Blackburn and Paul Griffin for assistance with production of the figures; NERC for financial support.

\section{References}

Andersson G (1976). Post-embryonic development of Lithobius forficatus (L), (Chilopoda: Lithobiidae). Ent Scand 7: 161-168.

Antonovics J, van Tienderen PH (1991). Ontoecogenophyloconstraints? The chaos of constraint terminology. Trends Ecol Evol 6: 166-168.

Archey G (1936). Revision of the Chilopoda of New Zealand. Rec Auck Inst Mus 2: 43-70.

Arthur W (1999). Variable segment number in centipedes: population genetics meets evolutionary developmental biology. Evol Dev 1: 62-69.

Arthur W (2000). The concept of developmental reprogramming and the quest for an inclusive theory of evolutionary mechanisms. Evol Dev 2: 49-57.

Arthur W (2001). Developmental drive: an important determinant of the direction of phenotypic evolution. Evol Dev 3: 271-278.

Arthur W, Farrow M (1999). The pattern of variation in centipede segment number as an example of developmental constraint in evolution. J Theor Biol 200: 183-191.
Arthur W, Kettle C (2001). Geographic patterning of variation in segment number in geophilomorph centipedes: clines and speciation. Evol Dev 3: 34-40.

Arthur W, Foddai D, Kettle C, Lewis JGE, Luczynski M, Minelli A (2001). Analysis of segment number and enzyme variation in a centipede reveals a cryptic species, Geophilus easoni sp nov, and raises questions about speciation. Biol J Linn Soc 74: 489-499.

Bastianello A, Minelli A (2001). Engrailed sequences from four centipede orders: strong sequence conservation, duplications and phylogeny. Dev Genes Evol 211: 620-623.

Bastianello A, Runco M, Burato P, Minelli A (2002). Hox gene sequences from the geophilomorph centipede Pachymerium ferrugineum (CL Koch, 1835) (Chilopoda: Geophilomorpha: Geophilidae): implications for the evolution of the Hox class genes of arthropods. Molec Phylog Evol 22: 151-161.

Bateson W (1894). Materials for the Study of Variation, Treated with Especial Regard to Discontinuity in the Origin of Species. Macmillan: London.

Beldade P, Koops K, Brakefield PM (2002). Developmental constraints versus flexibility in morphological evolution. Nature 416: 844-847.

Cheverud JM (1984). Quantitative genetics and developmental constraints on evolution by selection. J Theor Biol 110: 155-171.

Darwin C (1859). On the Origin of Species by Means of Natural Selection, or the Preservation of Favoured Races in the Struggle for Life. John Murray: London.

Dawkins R (1986). The Blind Watchmaker. Longman: London.

Dover GA (1982). Molecular drive: a cohesive mode of species evolution. Nature 299: 111-117.

Dworkin IM, Tanda S, Larsen E (2001). Are entrenched characters developmentally constrained? Creating biramous limbs in an insect. Evol Dev 3: 424-431.

Eason EH (1964). Centipedes of the British Isles. Warne: London.

Fisher RA (1930). The Genetical Theory of Natural Selection. Clarendon Press: Oxford.

Ford EB (1971). Ecological Genetics, 3rd edn. Chapman and Hall: London.

Fusco G (2001). How many processes are responsible for phenotypic evolution? Evol Dev 3: 279-286.

Gavrilets S (1997). Evolution and speciation on holey adaptive landscapes. Trends Ecol Evol 12: 307-312.

Geliva EA (1987). Meiotic drive in the sex chromosome system of the varying lemming, Dicrostomyx torquatus Pall (Rodentia: Microtinae). Heredity 59: 383-389.

Gould SJ (1977). Ontogeny and Phylogeny. Harvard University Press: Cambridge, MA.

Gould SJ (1989). A developmental constraint in Cerion, with comments on the definition and interpretation of constraint in evolution. Evolution 43: 516-539.

Gould SJ, Lewontin RC (1979). The Spandrels of San Marco and the Panglossian paradigm: a critique of the adaptationist programme. Proc $R$ Soc Lond B 205: 581-598.

Horneland EO, Meidell BA (1986). The epimorphosis of Strigamia maritima (Leach, 1817) (Chilopoda: Geophilidae). Ent Scand 17: 1127-1129.

Hughes CL, Kaufman TC (2002). Exploring the myriapod body plan: expression patterns of the ten Hox genes in a centipede. Development 129: 1225-1238.

Ingham PW (1988). The molecular genetics of embryonic pattern formation in Drosophila. Nature 335: 25-34.

Jeekel CAW (1964). Beitrag zur Kenntnis der Systematik und Ökologie der Hundertfsser (Chilopoda) Nordwestdeutschlands. Abhandlungen und Verhandlungen des naturwissenschaftlichen Vereins, Hamburg NF 8: 111-153.

Kettle C, Arthur W (2000). Latitudinal cline in segment number in an arthropod species, Strigamia maritima. Proc Roy Soc Lond B 267: 1393-1397.

Kettle C, Arthur W, Jowett T, Minelli A (1999). Homeotic transformation in a centipede. Trends Genet 15: 393.

Kettle C, Arthur W, Jowett T, Minelli A (2000). A homeotically- 
transformed specimen of Strigamia maritima (Chilopoda, Geophilomorpha), and its morphological, developmental and evolutionary implications. In: Wytwer J, Golovatch S (eds) Progress in Studies on Myriapoda and Onychophora Fragm Faun 43 (Suppl), pp 105-112, Warsaw.

Kettle C, Johnstone J, Jowett T, Arthur H, Arthur W (2002). The pattern of segment formation, as revealed by engrailed expression, in a centipede with a variable number of segments. Evol Dev 4 (in press).

Kirkpatrick M (1982). Quantum evolution and punctuated equilibria in continuous genetic characters. Am Nat 119: 833-848.

Lewis JGE (1981). The Biology of Centipedes. Cambridge University Press: Cambridge.

Mallet J (1986). Hybrid zones of Heliconius butterflies in Panama and the stability and movement of warning colour clines. Heredity 56: 191-202.

Maynard Smith J (1998) Shaping Life: Genes, Embryos and Evolution. Yale University Press: New Haven.

Maynard Smith J, Burian R, Kauffman S, Alberch P, Campbell J, Goodwin B et al (1985). Developmental constraints and evolution. Q Rev Biol 60: 265-287.

McKinney ML, McNamara KJ (1991). Heterochrony: The Evolution of Ontogeny. Plenum Press: New York.

Merrell DJ (1994). The Adaptive Seascape: The Mechanism of Evolution. University of Minnesota Press: Minneapolis.

Minelli A (1985). Post-embryonic development and the phylogeny of geophilomorph centipedes (Chilopoda). Bijdragen tot de Dierkunde 55: 143-148.

Minelli A (2000). Holomeric versus meromeric segmentation: a tale of centipedes, leeches and rhombomeres. Evol Dev 2: 35-48.

Minelli A, Bortoletto S (1988). Myriapod metamerism and arthropod segmentation. Biol J Linn Soc 33: 323-343.
Minelli A, Foddai D, Pereira LA, Lewis JGE (2000). The evolution of segmentation of centipede trunk and appendages. $J$ Zool Syst Evol Res 38: 103-117.

Misioch M (1978). Variation of characters in some geophilid chilopods. Abh Verh Naturwiss Ver Hamburg 21/22: 55-62.

Raff RA (1996). The Shape of Life: Genes, Development and the Evolution of Animal Form. Chicago University Press: Chicago.

Resnik D (1995). Developmental constraints and patterns: some pertinent distinctions. J Theor Biol 173: 231-240.

Riedl R (1978) Order in Living Organisms: A Systems Analysis of Evolution. Wiley, Chichester. (Translated by RPS Jefferies.)

Schwenk K (1995) A utilitarian approach to evolutionary constraint. Zoology 98: 251-262.

Wagner GP (1988). The significance of developmental constraints for phenotypic evolution by natural selection. In: de Jong G (ed) Population Genetics and Evolution, SpringerVerlag: Berlin.

Wallace AR (1870) Contributions to the Theory of Natural Selection: A Series of Essays. Macmillan: London.

Wallace AR (1897). Darwinism: An Exposition of the Theory of Natural Selection, with some of its Applications. Macmillan: London.

Whitlock MC (1995). Variance-induced peak shifts. Evolution 49: 252-259.

Whyte LL (1965). Internal Factors in Evolution. Tavistock Publications: London.

Wimsatt WC (1986). Developmental constraints, generative entrenchment, and the innate-acquired distinction. In: Bechtel W (ed) Integrating Scientific Disciplines, Martinus-Nijhoff: Dordrecht.

Yampolsky LY, Stoltzfus A (2001). Bias in the introduction of variation as an orienting factor in selective evolution. Evol Dev 3: 73-83. 